\title{
USING FACE MASKS IN THE CLASSROOM: THE EFFECT ON THE INDOOR ENVIRONMENT PARAMETERS AND FACE THERMOPHYSIOLOGICAL REACTIONS
}

\author{
ANGELOVA, R. A. ${ }^{*}$ - VELICHKOVA, R. \\ Centre for Research and Design in Human Comfort, Energy and Environment (CERDECEN), \\ Technical University of Sofia, 8 Kliment Ochridski blv., 1000 Sofia, Bulgaria \\ *Corresponding author \\ e-mail: joy_angels@abv.bg,radost@tu-sofia.bg \\ (Received $7^{\text {th }}$ Jun 2021; accepted $28^{\text {th }}$ Oct 2021)
}

\begin{abstract}
Masks have been recommended as a protective tool for effectively combating the COVID-19 pandemic. In many countries, masks are required indoors, but the obligation temporarily and sporadically extends to all public places indoors and outdoors in some regions. Our study investigated the effect of wearing face masks in the classroom on the indoor environmental parameters and the human body experimentally. The study was performed at the Technical University of Sofia with 14 volunteers during regular lecture classes. Two stages were considered: with and without face masks. Measurement of the indoor environment parameters, oxygen $\left(\mathrm{O}_{2}\right)$ and carbon dioxide $\left(\mathrm{CO}_{2}\right)$ concentration was continuously performed. Thermal image analysis was used to obtain the face thermograms of the participants. The results clearly showed the retention effect of the face masks on the exhaled air, leading to lower $\mathrm{CO}_{2}$ concentration in the classroom and higher $\mathrm{O}_{2}$ concentration and humidity. It was also found that the continuous wear of a face mask for 40-45 min provoked an increment of the facial skin temperature under the mask to $37^{\circ} \mathrm{CC}$ and even more. The rise of the temperature of the inner cantus of the eye showed that the face mask triggered the body's thermoregulation, causing thermophysiological reactions.
\end{abstract}

Keywords: COVID-19, infrared thermography, carbon dioxide concentration, thermophysiological comfort, university classroom

\section{Introduction}

The SARS-CoV2 (COVID-19) pandemic has led to people being required to wear protective face masks. In many countries, the requirement is limited to wearing masks indoors - in buildings and vehicles, but in some regions, the obligation temporarily and sporadically extends to all public places indoors and outdoors. Masks have been recommended as a protective tool for massively combating the COVID-19 pandemic in China (Wang et al., 2020), although their use varies by time and province (Feng et al., 2020).

Health organisations, politicians and societies are seeking sufficient evidence of the benefits of restrictive measures (one of which is wearing masks) as a tool in the fight against COVID-19 in the light of the existing context: a complex environment for making solutions, difficult to foresee spread of the pandemic, fast development of new research, and continuous increase in the number of people infected and deaths in many countries.

Though there is no a deficit anymore of N95 respirators (classified by the National Institute of Occupational Safety in the United States) or FFP2 respirators (certified by the European Union and filtering over $94 \%$ of airborne particles), masks for hospital use (Smith et al., 2020) and ordinary textile masks are primarily in use. The American and European Centers for Disease Control (Howard et al., 2021) recommended this practical public-use approach. The use of face masks and their effectiveness can be considered 
from different points of view: medical (e.g., to what extent they are effective against viral particles of cell size), social (e.g., how they protect risk groups), psychological (e.g., to what extent they limit facial expression, as an essential part of communication). At the same time, contradictory data exist on the effect of face masks as a tool in the fight against SARS-CoV2 (Rieger, 2020).

During the COVID-19 pandemic in Hong Kong, a telephone study found increased adherence to wearing masks in public places; with no mandatory requirements, the number of people wearing masks outside the home increased from $74.5 \%$ to $97.5 \%$ in just three weeks (Cowling et al., 2020). Similar studies were reported during the SARS pandemic in 2003: $79 \%$ of people reported wearing masks outside the home voluntarily (Leung et al., 2004). These facts suggest that society raises its awareness of risk and is more inclined to adhere to prevention strategies. Simultaneously, the widespread use of masks is a visual reminder of the need for physical distancing, which is among the safest strategies to prevent SARS-CoV2 transmission. Third, the wearing of masks by all avoids public stigmatisation of virus carriers or patients, as described in other diseases, e.g., tuberculosis (Buregyeya et al., 2012).

Several research papers dealing with the use of textile and surgical masks focused mainly on the effectiveness of filtration against aerosols (liquid or dry) with a particle size from $0.01 \mu \mathrm{m}$ to $10 \mu \mathrm{m}$ (Van der Sande et al., 2008; Rengasamy et al., 2010; Chughtai et al., 2013; Davies et al., 2013; Shakya et al., 2017; Konda et al., 2020). The study of Aydin et al. (2020) also proposed a method for assessing the retention capacity of textile masks to larger droplets released when coughing, sneezing or talking. However, a few studies have been conducted with the start of the COVID-19 pandemic to evaluate the effectiveness of wearing a mask over time and assess the individual's comfort and possible side effects. Among the first exceptions was the editorial letter of Lazzarino et al. (2020). Perhaps, the reason for this was that for the first time, the policymakers put on the agenda the need for long-term wearing of masks by various segments of the population outside the medical institutions. Some of these segments involve children or adults with side effects of the respiratory tract (asthma, respiratory allergies).

The side effects of the widespread, long-term and continuous use of masks can be summarised as follows (Desai et al., 2020; Kyung et al., 2020; Lazzarino et al., 2020; Liu et al., 2020a; World Health Organization, 2020).

- Psychological:

- They create a false sense of proper measures taken against the infection and neglect other measures (handwashing, distance) (World Health Organization, 2020).

- $\quad$ They are associated with religious behaviour patterns (covering the face), which is unacceptable for some Western societies (Liu et al., 2020a).

- Behavioral:

- Touching the masks with hands (due to the mask's displacement on the face) increases the risk of infection (Desai et al., 2020; World Health Organization, 2020).

- Shortening the distance to the interlocutor: due to the inability to follow the lips, some people do not understand speech well and unconsciously approach the interlocutor.

- $\quad$ More frequent eye touch since part of the exhaled air is directed to the eyes increases the risk of infection. 
- With an effect on the health and comfort:

- Change in respiration rate, blood oxygen saturation and exhaled $\mathrm{CO}_{2}$ levels before and after using the N95 mask (Kyung et al., 2020).

- Creation of a humid environment favourable for the spread of the virus (Lazzarino et al., 2020).

A recent study (Liu et al., 2020b) reported measurements of the face temperature when using both N95 and surgical masks, finding that N95 masks provoked more significant thermal discomfort and higher facial skin temperature. Another study (Scarano et al., 2020) evaluated the influence of different face masks on human comfort indoors, aiming to facilitate selecting different masks from the rational and scientific point of view.

The aim of our study was to evaluate the effect of wearing face masks on people's comfort in a university classroom and on the parameters of the indoor environment. The idea was provoked by the episodic requirement that students in schools and universities, together with their teachers, stay in the classrooms with masks. Our hypotheses were that wearing face masks could provoke local thermal discomfort and inhibit the transition of exhaled air to the environment. The thermal comfort was evaluated based on infrared thermal imaging and consequent processing of the thermograms. Sensors for measuring the air temperature, relative humidity, pressure, oxygen $\left(\mathrm{O}_{2}\right)$ concentration and carbon dioxide $\left(\mathrm{CO}_{2}\right)$ concentration were used together with software to monitor the parameters change directly.

\section{Materials and methods}

\section{Participants and environmental conditions}

The study was performed in October 2020 at the Technical University of Sofia (Sofia, Bulgaria) in a classroom at Building 2 (Fig. l) with installed heating, ventilation and air conditioning (HVAC) system. The classroom volume was $204 \mathrm{~m}^{3}(11.8 \mathrm{~m}$ length, $5.4 \mathrm{~m}$ width, and $3.2 \mathrm{~m}$ height).

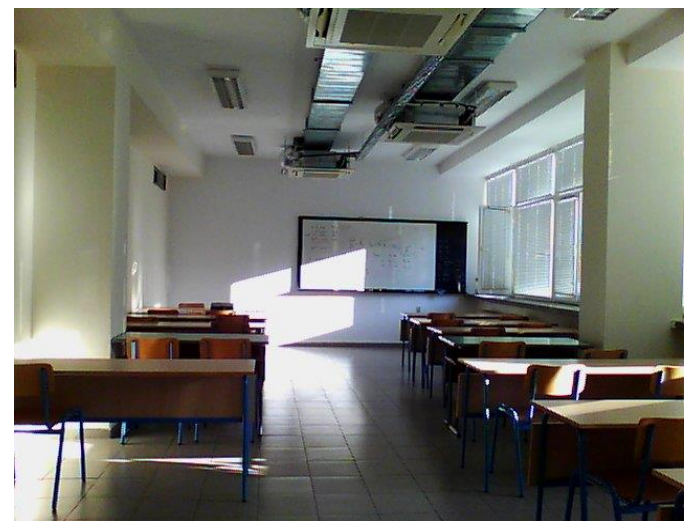

(a)

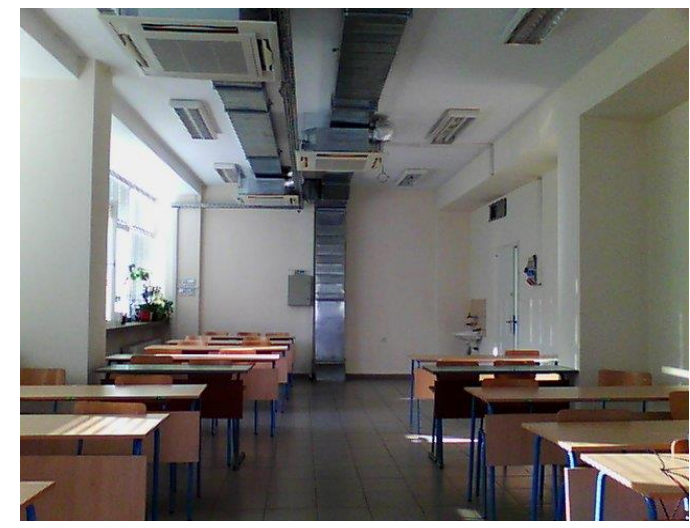

(b)

Figure 1. The university classroom with an HVAC system: (a) View to the front zone; (b) view to the back zone

The measurements were done during regular lectures, with twelve volunteers, students (age 21-28 years). Two teachers (age 40 and 51) also participated in the 
experiment: one lecturing and one dealing with the infrared measurements. The participants declared that they had no symptoms of COVID-19 or influenza. They gave permission for the use of their thermograms' data.

The field study was performed following the current governmental and university prescriptions (as of October 2020). In that period, the students and teachers were not obliged to use face masks in the classrooms, whilst the distance between the working places and occupants were large enough. The particular classroom could accommodate 24 people, and in this case, only $50 \%$ of its seats were occupied.

The room air temperature was set to $22{ }^{\circ} \mathrm{C}$, recirculation mode of the HVAC system. All windows and the door were closed to avoid entering of outside air.

The outdoor temperature was $11^{\circ} \mathrm{C}$ at the beginning of the measurements and $11.8^{\circ} \mathrm{C}$ at the end. The relative humidity was $65 \%$.

\section{Face masks}

Surgical face masks of a disposal type with loops (Etropal JSC, Etropole, Bulgaria) were given to all participants in the experiment (Fig. 2). The masks correspond to ISO 13485 (2016), and EN 14683 + AC (2019).

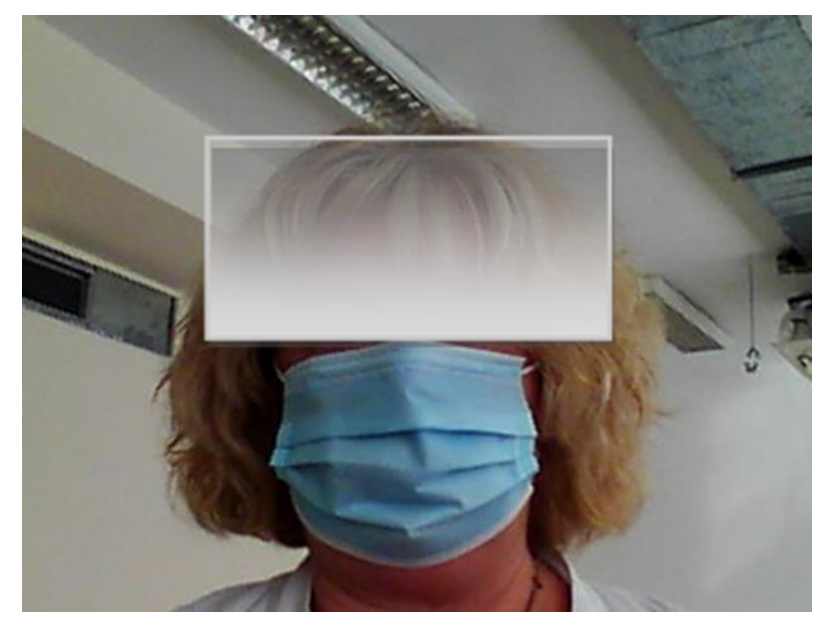

Figure 2. The used face masks

Three non-woven layers, whose microscopic views are presented in Figure 3, form the mask. The outer one (Fig. 3a) protects from droplets, the middle one (Fig. 3b) filters viruses (over 95\%), particles (over 98\%) and bacteria (over 98\%) (ISO 13485, 2016; EN $14683+$ AC, 2019).

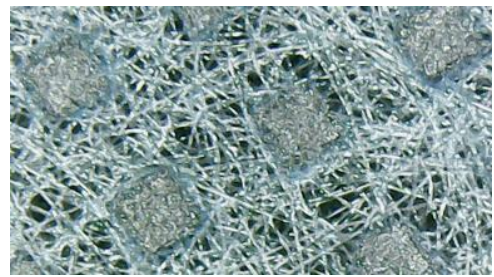

(a)

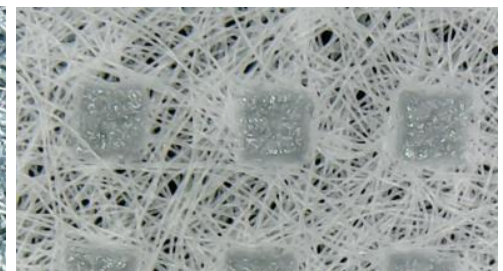

(b)

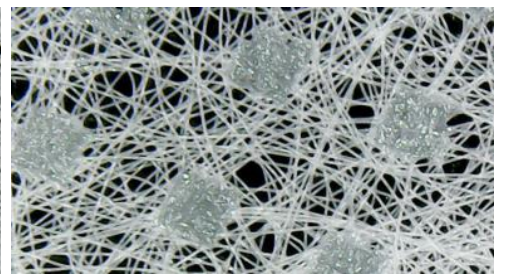

(c)

Figure 3. Microscopic view of the mask layers: (a) Outer layer (blue); (b) middle layer (invisible); (c) inner layer (white) 
According to ISO 13485 (2016) and EN 14683+AC (2019) the inner one (Fig. 3c) assures the comfort of the skin face. The average thickness of a mask (from 10 measurements) was $0.92 \mathrm{~mm}$.

\section{Measurements}

During the experiment, the air temperature, relative humidity and pressure were continuously recorded with a time step of $5 \mathrm{~s}$. The change in the oxygen $\left(\mathrm{O}_{2}\right)$ and carbon dioxide $\left(\mathrm{CO}_{2}\right)$ concentration in the room was also monitored continuously with a time step of $5 \mathrm{~s}$. As the $\mathrm{CO}_{2}$ concentration was of primary interest, two $\mathrm{CO}_{2}$ sensors (K30 FR Fast Response 10000 ppm $\mathrm{CO}_{2}$ sensor of CO2Meter, USA) were used - in the front and the back zone of the classroom (Fig. 1). A sensor for joint monitoring of the $\mathrm{O}_{2}$ concentration, air temperature, relative humidity and pressure (CM-4X of CO2Meter, USA) was placed in the middle of the classroom. The results were red using the GasLab specialised software (CO2Meter, USA).

The remote recording of the face temperature (with and without face masks) was done with FLIR E6 infrared thermal camera (FLIR Systems Inc., Wilsonville, OR, US) with the following parameters: thermal sensitivity $<0.06{ }^{\circ} \mathrm{C} ;-20{ }^{\circ} \mathrm{C}$ to $250{ }^{\circ} \mathrm{C}$ temperature range; IR $19200(160 \times 120)$ pixels resolution; Imaging resolution $320 \times 240 ; 0.1$ to 1 adjustment of the radiation; 3 measurement modes. The recording was done at $0.5 \mathrm{~m}$ away from the face of the person.

\section{Experimental protocol}

The study involved two stages (Stage 1 and Stage 2) with the same protocol. The HVAC system was set in a recirculation mode with $22{ }^{\circ} \mathrm{C}$ air temperature. All windows and the door were closed to avoid entering fresh air.

After entering the classroom, the participants were asked to sit evenly distributed among the workplaces: 1 person per a table (Fig. 4). They were also requested not to change their clothing ensemble during the experiment.

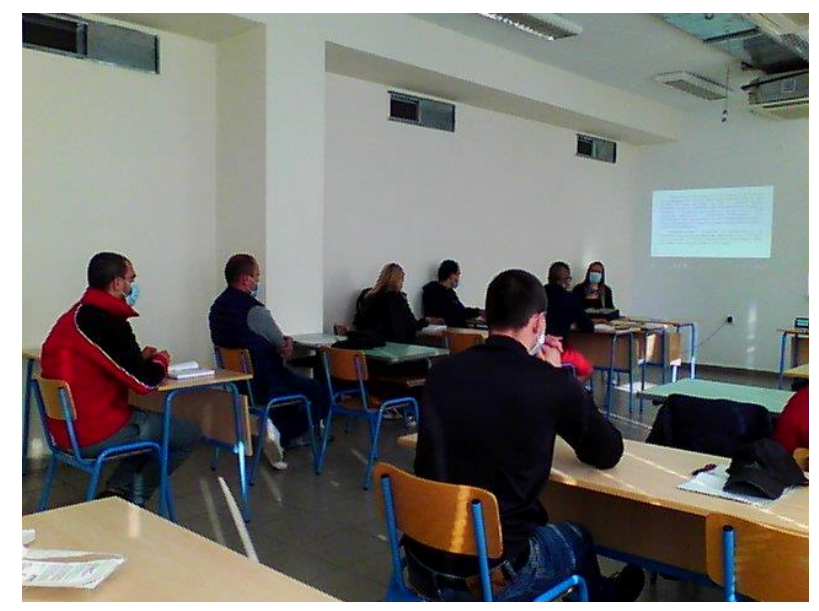

Figure 4. During the measurements, Stage 1

In Stage 1, the participants wore surgical masks. The duration of the lecture class was $45 \mathrm{~min}$, which resulted in a $2600 \mathrm{~s}$ measurement period (seconds at the beginning of the lecture were omitted to equalize the recordings from all sensors). The participants 
were sitting, listening to the lecture and taking notes. Five thermograms were taken of each person: after the acclimatization (a reference thermogram) at the beginning of the class; 20 min after the first measurement; and at the end of the class - a thermogram with the mask and a thermogram of the face immediately after the mask was taken off.

Stage 2 took place after a 30 min break. All windows were open during the break. The students took the same seats in the classroom as during Stage 1. They did not wear masks. Figure 5 illustrates the experimental protocol in Stage 1.

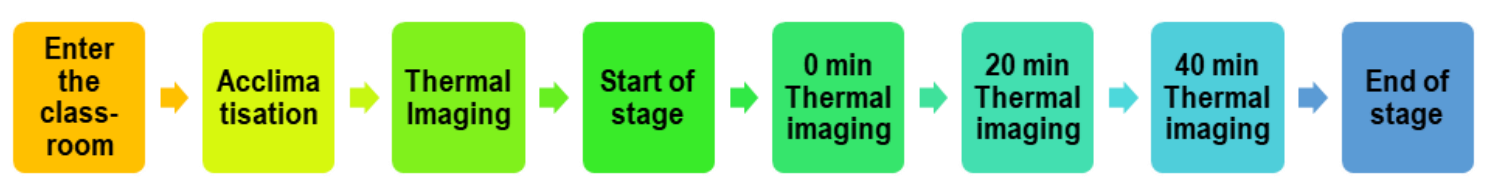

Figure 5. The experimental protocol

\section{Statistical analysis}

All data were statistically analysed using Excel Data Analysis ToolPack. The experimental results are presented as the average value \pm standard deviation. The Student test (t-test) was performed to evaluate the existence of a statistically proven difference between the average values in each group. The significance level $\alpha$ was set to 0.05 .

\section{Results}

\section{Indoor environmental parameters}

Stage 1 (with masks)

Figure 6 presents the change in the room air temperature, relative humidity and pressure during Stage 1 when the participants wear face masks. Though the temperature maintained by the HVAC system was set to $22^{\circ} \mathrm{C}$, the average value of the temperature in the room was $23.66 \pm 0.35^{\circ} \mathrm{C}$. The increment was due to the radiation heat from the inhabitants, their breath and the radiation heat from the windows (facing to the East) on that sunny day.

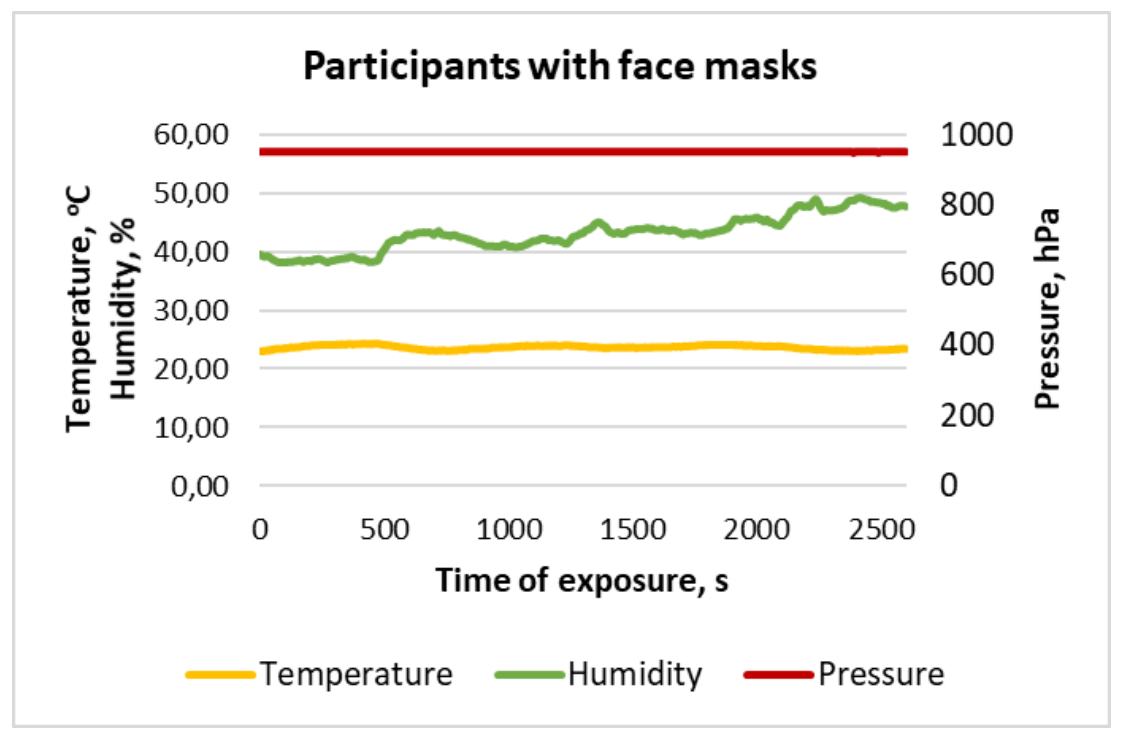

Figure 6. Indoor environmental parameters, Stage 1 
The air pressure remained constant, $950 \pm 0.06 \mathrm{hPa}$.

The air humidity increased with the time from $38 \%$ to $49.2 \%$ due to the exhalation of the inhabitants. The recirculation mode of the ventilation system did not allow the entrance of outside air. The average air humidity during Stage 1 was $43.07 \pm 3.07 \%$.

Figure 7 presents the results for the $\mathrm{CO}_{2}$ concentration, summarising the data from the sensors in the front and back zone of the room. The back zone sensor measured higher $\mathrm{CO}_{2}$ concentration in the classroom than the front one. The statistical analysis of the data proved the difference between the readings of the two sensors $\left(t_{\text {stat }}=130\right.$, $\left.t_{\text {crit }}=1.96, \alpha=0.05\right)$. The Pearson correlation (0.98) showed that a linear dependence exists between the two sets of data.

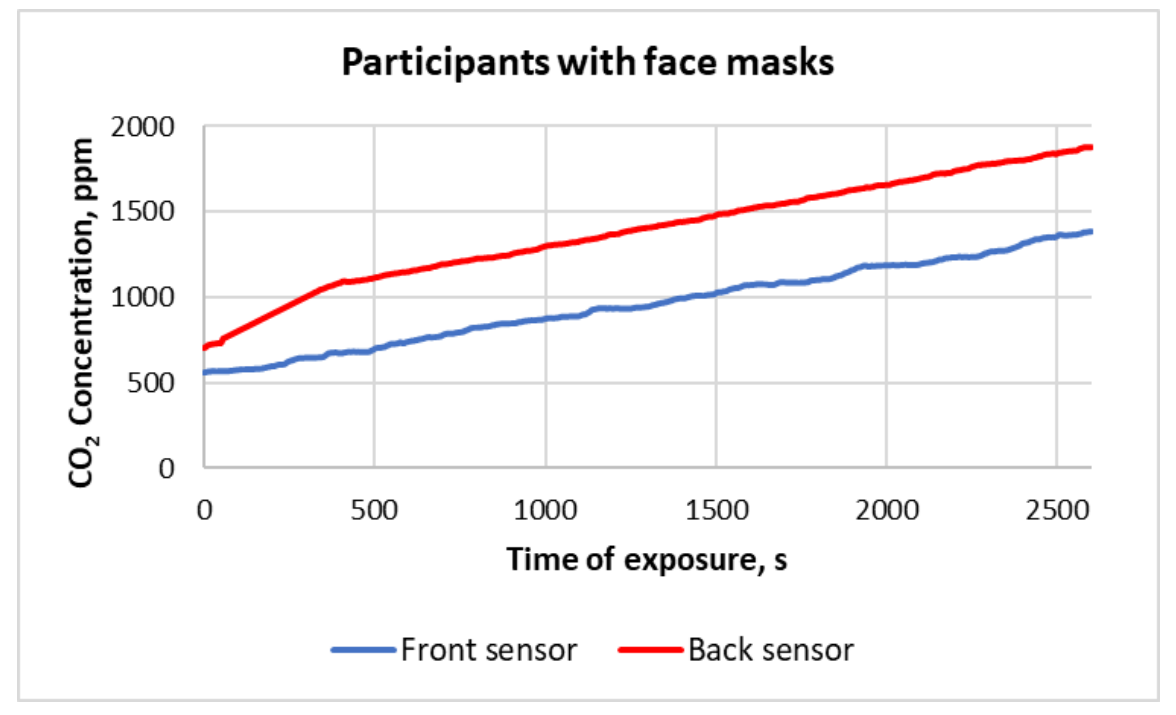

Figure 7. Carbon dioxide concentration, Stage 1

\section{Stage 2 (no masks)}

Figure 8 summarises the results for the room air temperature, relative humidity and pressure in Stage 2 when the participants did not wear face masks. The temperature in the room was $23.81 \pm 0.28{ }^{\circ} \mathrm{C}$, again higher than the set temperature of $22{ }^{\circ} \mathrm{C}$. The air pressure remained constant, $949 \pm 0.33 \mathrm{hPa}$.

The air humidity increased during the lecture from $41.1 \%$ to $50.2 \%$. The average air humidity during Stage 2 was $44.29 \pm 1.93 \%$.

Figure 9 visualizes the results for the $\mathrm{CO}_{2}$ concentration, measured by the front and back sensors in the classroom. Similar to Figure 7, the $\mathrm{CO}_{2}$ concentration in the back zone of the classroom was higher than in the front zone. The statistical analysis showed a proven difference between the readings of the two sensors $\left(t_{\text {stat }}=182.72, t_{\text {crit }}=1.96\right.$, statistical level $\alpha=0.05)$. The Pearson correlation (0.998) showed that a linear dependence exists between the two sets of data.

\section{Comparison between Stage 1 and Stage 2}

In Stage 1, the average air temperature in the classroom was $23.66 \pm 0.34{ }^{\circ} \mathrm{C}$ and in Stage 2 was $23.81 \pm 0.28^{\circ} \mathrm{C}$. Though the average values were similar, the statistical comparison showed a proven difference between the two sets of data: $t_{\text {stat }}=8.97$, $\mathrm{t}_{\text {crit }}=1.96, \alpha=0.05$. 


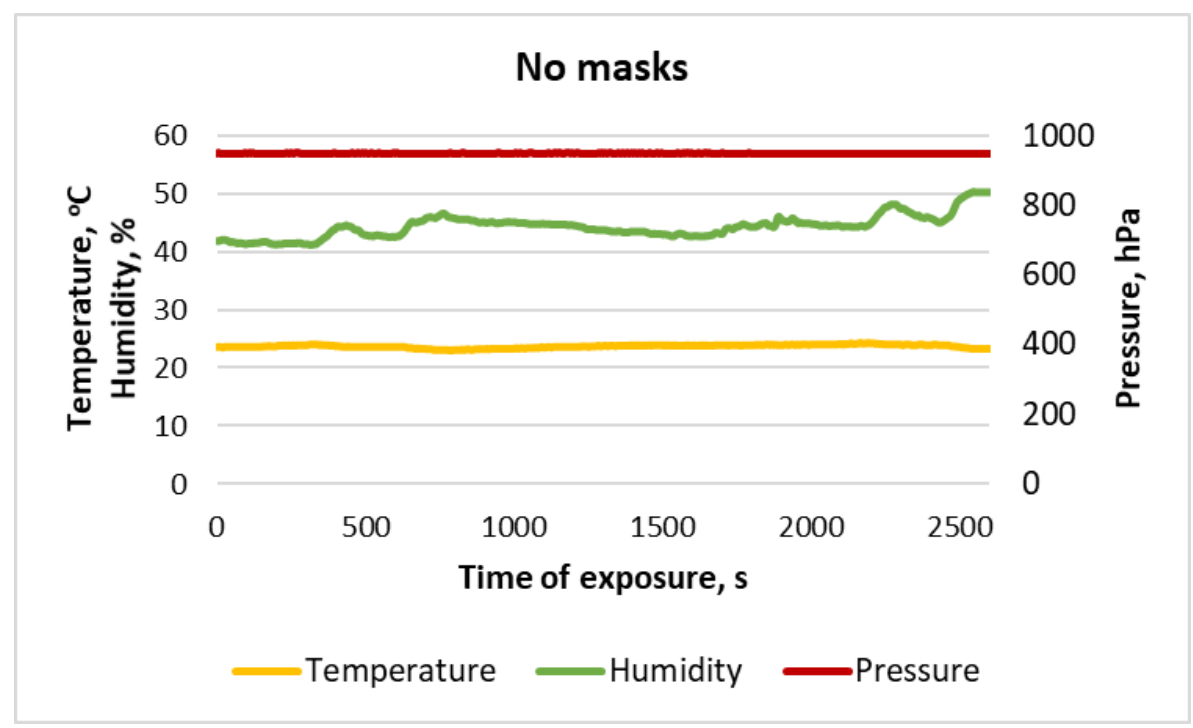

Figure 8. Indoor environmental parameters, Stage 2

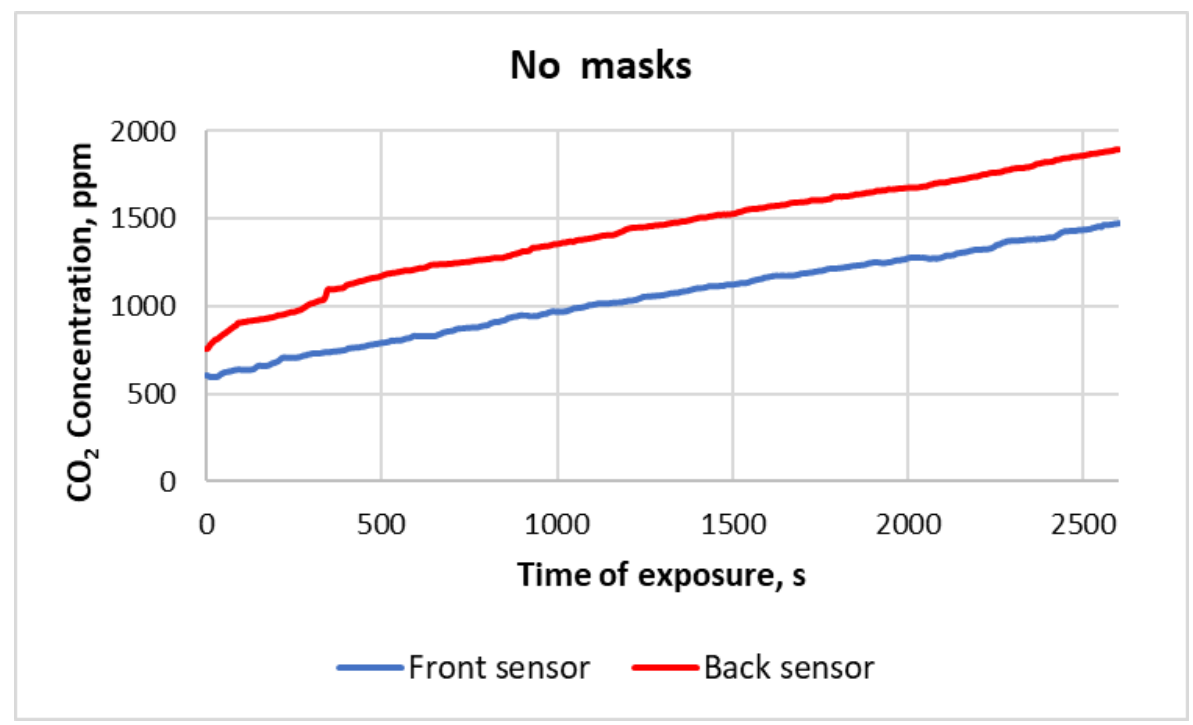

Figure 9. Carbon dioxide concentration, Stage 1

The average humidity in Stage 1 was $43.07 \pm 3.07 \%$, while in Stage 2, it was $44.29 \pm 1.93 \%$. The statistical analysis allowed us to conclude that there was a proven effect of wearing face masks on the air humidity in the classroom: $t_{\text {stat }}=12.5$, $\mathrm{t}_{\text {crit }}=1.96, \alpha=0.05$.

The results for the oxygen $\left(\mathrm{O}_{2}\right)$ concentration in the two stages are compared in Figure 10. The tendency is towards slight decrement due to the recirculation mode and the breathing of the inhabitants. However, it is visible that much more fluctuations in the $\mathrm{O}_{2}$ concentration were present in Stage 2, while in Stage 1, the decrement line was smoother. The average value of the $\mathrm{O}_{2}$ concentration in Stage 1 was $202924.8 \pm 306.1 \mathrm{ppm}$. In Stage 2, the average value of the $\mathrm{O}_{2}$ concentration was quite similar: $203041.6 \pm 392.1 \mathrm{ppm}$. The statistical analysis showed that the two data sets were statistically different: $\mathrm{t}_{\text {stat }}=13.468, \mathrm{t}_{\text {crit }}=1.96, \alpha=0.05$. 


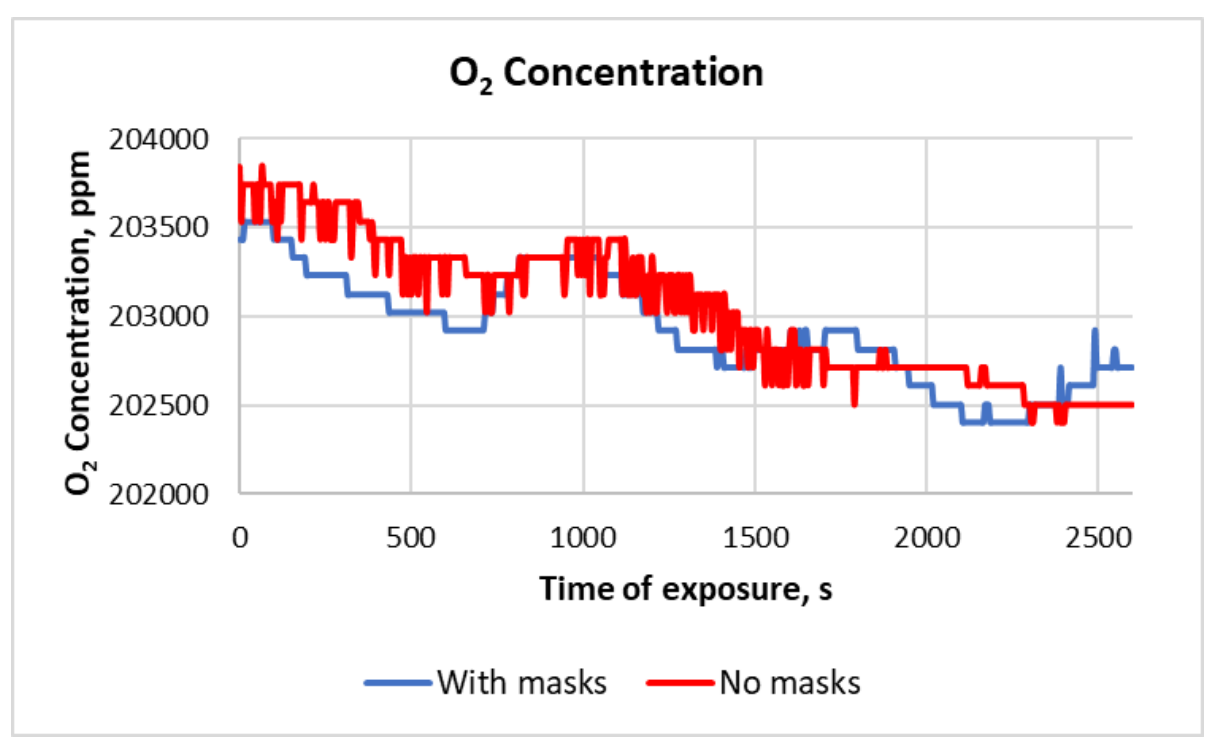

Figure 10. Oxygen concentration during Stage 1 and Stage 2

Figure 11 illustrates the comparison between the $\mathrm{CO}_{2}$ concentration, measured in the fronts zone of the classroom in Stage 1 and Stage 2. When the participants wore face masks, the $\mathrm{CO}_{2}$ concentration was $962 \pm 238 \mathrm{ppm}$. When the participants were without masks, the $\mathrm{CO}_{2}$ concentration was $1051 \pm 244 \mathrm{ppm}$. It is noteworthy that the average value of $\mathrm{CO}_{2}$ concentration in Stage 2 was higher by $90 \mathrm{ppm}$, but the standard deviation in both measurements was almost the same. The statistical check showed a proven difference between the two data groups, i.e. the presence of masks affected the $\mathrm{CO}_{2}$ concentration: $\mathrm{t}_{\text {stat }}=125.247, \mathrm{t}_{\text {crit }}=1.96, \alpha=0.05$.

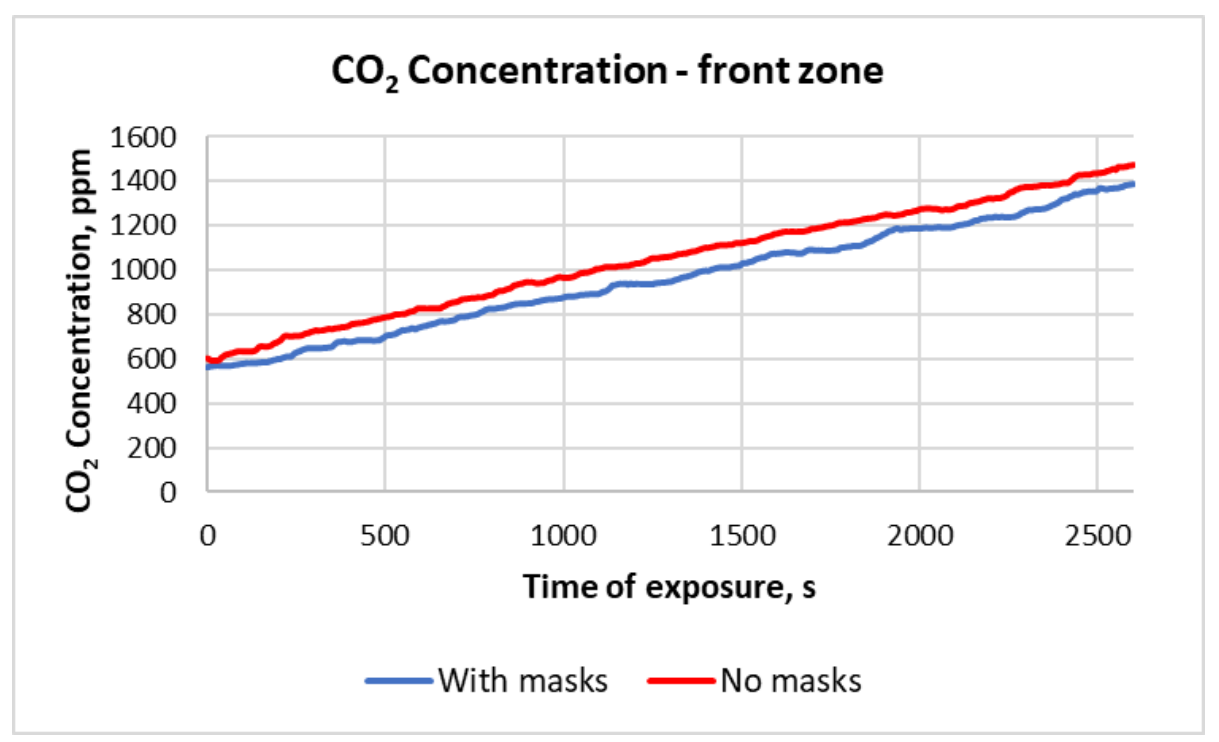

Figure 11. Carbon dioxide concentration in the front zone of the classroom during Stage 1 and Stage 2

Figure 12 compares the results for the $\mathrm{CO}_{2}$ concentration, measured in the back zone of the classroom in Stage 1 and Stage 2. When the participants were with face masks, 
the $\mathrm{CO}_{2}$ concentration was $1389 \pm 302 \mathrm{ppm}$. When the participants were without masks, the $\mathrm{CO}_{2}$ concentration was $1434 \pm 287 \mathrm{ppm}$. The statistical analysis showed a proven difference between the two data sets, i.e. the use of masks affected the $\mathrm{CO}_{2}$ concentration: $\mathrm{t}_{\text {stat }}=42.246, \mathrm{t}_{\text {crit }}=1.96, \alpha=0.05$.

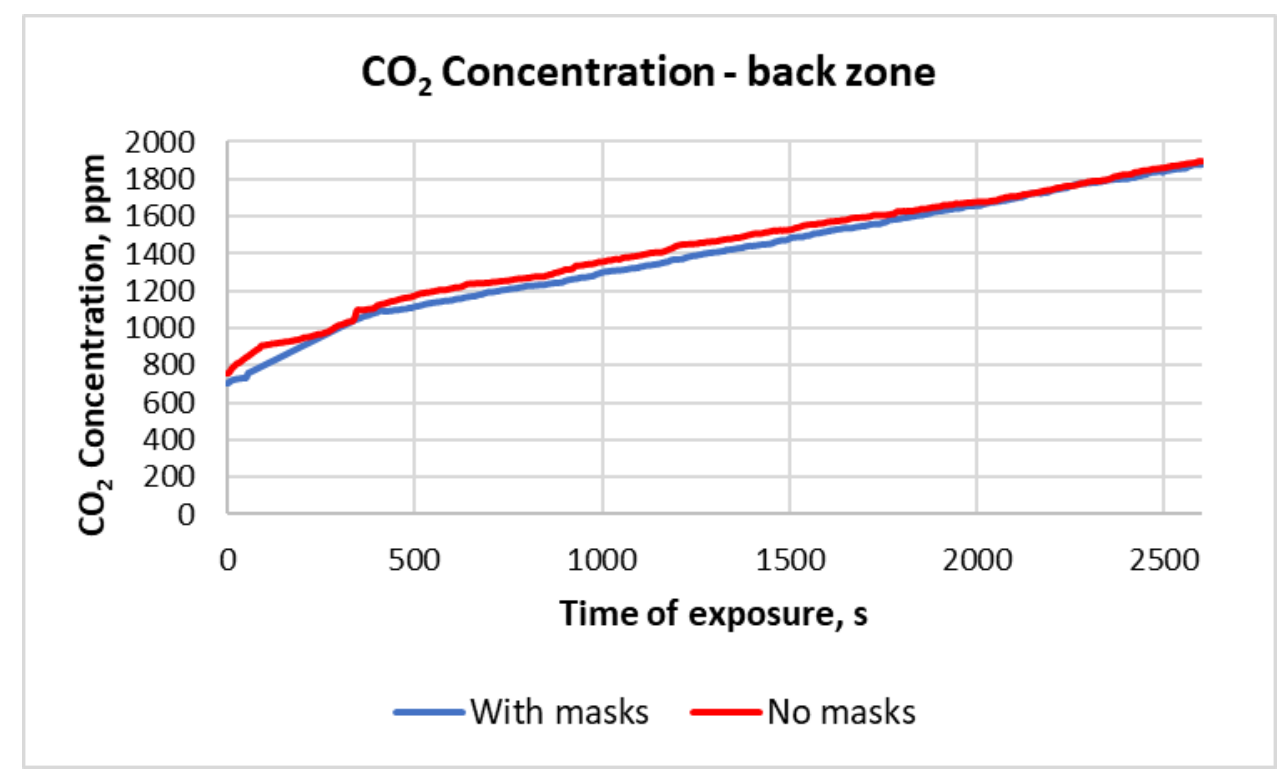

Figure 12. Carbon dioxide concentration in the back zone of the classroom during Stage 1 and Stage 2

\section{Thermal infrared imaging}

Figure 13 shows the changes in the surface temperature of the face mask in Stage 1. For all participants (except Participant \#4), the surface temperature of the mask was lowest at the beginning of the stage. The heat exchange "face - mask" led afterwards to an increment of the temperature of the mask surface. The increment was more significant in the first $20 \mathrm{~min}$ than in the second half of Stage 1. The average temperature of the mask surface was $30.04 \pm 0.68^{\circ} \mathrm{C}$ at the start of Stage 1, $31 \pm 0.74{ }^{\circ} \mathrm{C}$ in the middle of the stage and $31.18 \pm 0.7^{\circ} \mathrm{C}$ at the end.

The analysis proved the statistical difference between the mask temperature at the beginning and in the middle of Stage $1\left(\mathrm{t}_{\mathrm{stat}}=3.52, \mathrm{t}_{\text {crit }}=2.16, \alpha=0.05\right)$. However, the difference between the mask temperature in the middle and at the end of Stage 1 was not proven statistically $\left(\mathrm{t}_{\text {stat }}=0.94, \mathrm{t}_{\text {crit }}=2.16, \alpha=0.05\right)$.

The results for the change of the skin face temperature at the beginning of Stage 1 (after the acclimatisation) and at the end of the stage (immediately after the mask was taken off) are summarised in Figure 14. The face skin temperature at the beginning of Stage 1 was $35.34 \pm 0.92{ }^{\circ} \mathrm{C}$. The face skin temperature at the end of Stage 1 was $36.84 \pm 0.50{ }^{\circ} \mathrm{C}$. The statistical analysis showed that the difference between the two data sets was statistically proven: $t_{\text {stat }}=6.16, t_{\text {crit }}=2.16, \alpha=0.05$. Hence, the changed factor - the presence of a mask on the face, influenced the skin temperature of the face.

The registered temperature of the skin face above $37^{\circ} \mathrm{C}$ led to additional analysis of the thermograms. The thermograms were processed to show in red areas the skin temperature above a certain limit. This limit was set to $36.7^{\circ} \mathrm{C}$ for the reference thermograms (after the acclimatisation in Stage 1) and the thermograms of the face 
immediately after the removal of the masks. An additional limit was set for the thermograms at the end of Stage 1: $37^{\circ} \mathrm{C}$. Obviously, the coloured in red area was smaller compared to the thermograms with a temperature limit above $36.7^{\circ} \mathrm{C}$. Figure 15 summarises the thermal infrared (IR) images of all participants in Stage 1.

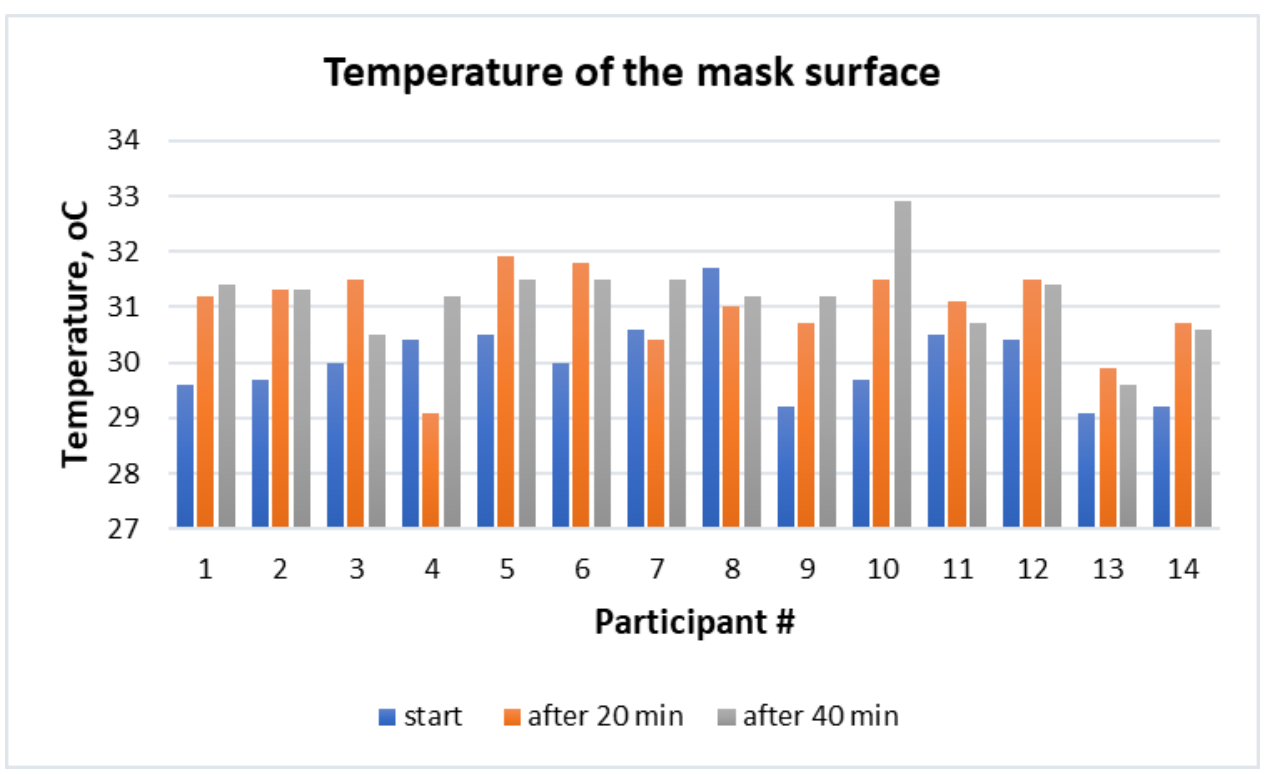

Figure 13. The temperature on the mask surface at the beginning of Stage 1 (start), in the middle (after $20 \mathrm{~min}$ ) and at the end of the stage (after $40 \mathrm{~min}$ )

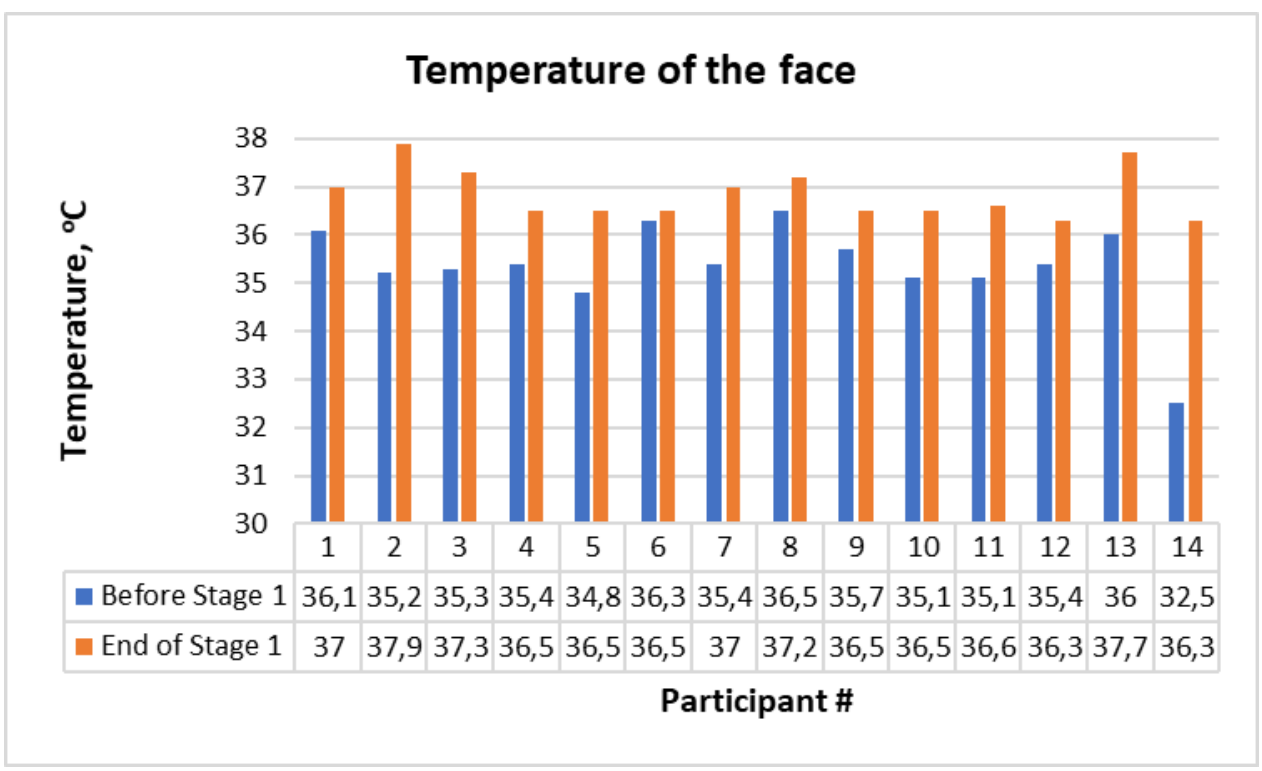

Figure 14. The temperature of the face before Stage 1 (after the acclimatisation) and after the mask taking off at the end of Stage 1

Figure 16 shows the results of determining the temperature of the inner canthus of the eye (the place where the upper and lower eyelids meet). Twelve measurements were considered, as two of the participants wore glasses when the thermograms were taken. 
The average temperature of the inner cantus before Stage 1 was $36.35 \pm 0.7^{\circ} \mathrm{C}$, and after wearing the masks, the temperature increased to $37.08 \pm 0.22^{\circ} \mathrm{C}$. The statistical analysis proved the existence between the two sets of measurements: $t_{\text {stat }}=3.9$, $\mathrm{t}_{\text {crit }}=2.2, \alpha=0.05$.

The average temperature of the inner cantus of the eye before Stage 1 was $36.35 \pm 0.7^{\circ} \mathrm{C}$, and after wearing the masks, the average temperature increased to $37.08 \pm 0.22{ }^{\circ} \mathrm{C}$. The statistical analysis proved the difference between the two sets of measurements:

$$
\mathrm{t}_{\text {stat }}=3.9, \mathrm{t}_{\text {crit }}=2.2, \alpha=0.05 \text {. }
$$

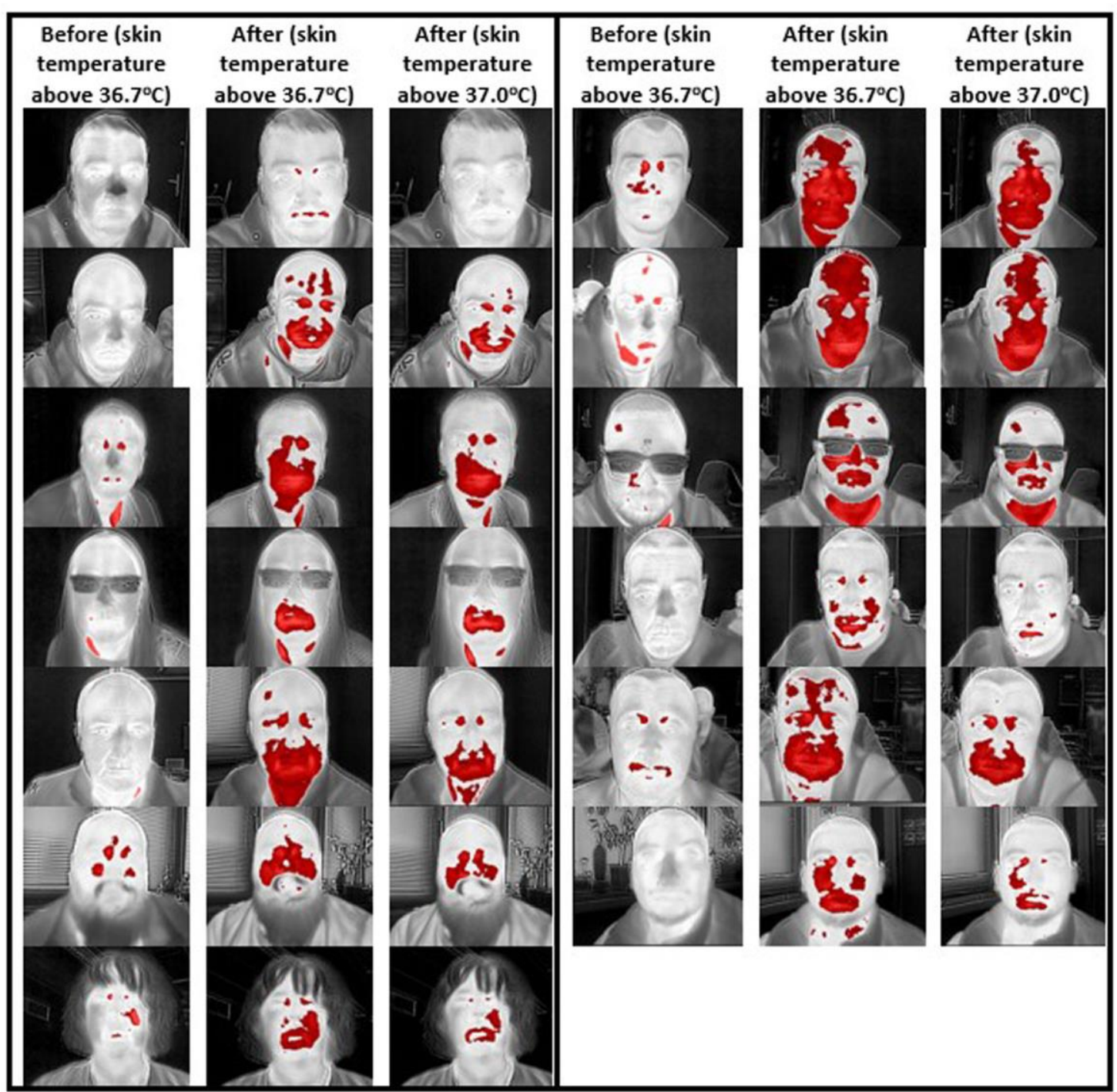

Figure 15. Thermograms of the participants

\section{Discussion}

The study's main result is that the continuous use of face masks in the classroom for 40-45 min leads to statistically proven changes in both the indoor environment and thermophysiological reactions of the participants. The effect on the indoor environment 
is due to the presence of the mask and the formation of a stagnation microzone between the face and the mask, which affects the inhaled and exhaled air.

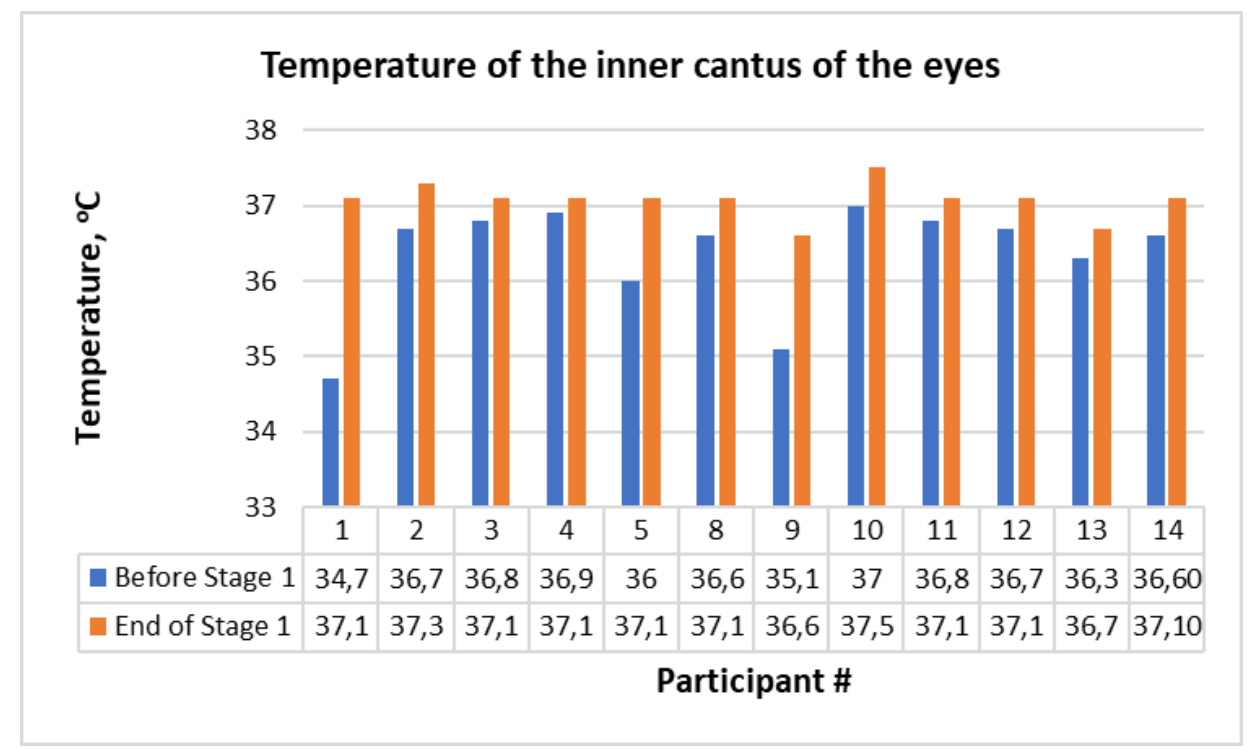

Figure 16. The temperature of the inner cantus of the eye before Stage 1 (after the acclimatisation) and after the mask taking off at the end of Stage 1

To check this hypothesis, additional measurements were performed with the same type of masks and three of the participants. The $\mathrm{CO} 2$ concentration sensor was firmly fixed on a person's face under a face mask near the mouth. As the zone under the mask was of primary interest, it was considered that the day of the measurement and the classroom indoor environment conditions would not be significant. The idea was only to measure the $\mathrm{CO}_{2}$ concentration under the face mask with a step of $5 \mathrm{~s}$. The measurements were performed 6 times with three volunteers (two measurements for a person).

Figure 17 shows a typical result from the measurements. At the beginning of the measurement, the person is with the face mask under the chin. The $\mathrm{CO}_{2}$ concentration measured is $1165 \mathrm{ppm}$, which is higher than the $\mathrm{CO}_{2}$ concentration of the air in the room $(840 \mathrm{ppm})$. This could be due to the human breathing influencing the sensor on the face. After lifting the mask on the face, covering both the mouth and nose, the sensor was left on the face. In $15 \mathrm{~s}$, the $\mathrm{CO}_{2}$ concentration reached $10000 \mathrm{ppm}$, which was the top of the sensor sensitivity (designed for indoor environment measurements).

When the face was uncovered again, the $\mathrm{CO}_{2}$ concentration decreased but much slower. The new covering of the face with the mask resulted in a new fast increase (approx. $15 \mathrm{~s}$ ) of the $\mathrm{CO}_{2}$ concentration under the mask (the second pick in Fig. 17). Indeed, this preliminary result is only a sign of the process under the face mask and need further investigation with a $\mathrm{CO}_{2}$ concentration sensor with a higher measurement range. Using a special device (Sofronova et al., 2021), this would be a point of further research within the project.

The comparison between the indoor environmental parameters when the participants were with and without face masks showed a significant, statistically proven change in the $\mathrm{CO}_{2}$ concentration in the classroom. The use of face masks led to lower $\mathrm{CO}_{2}$ concentration in the air. An explanation could be the retention of some of the exhaled $\mathrm{CO}_{2}$ in the microzone under the mask. 


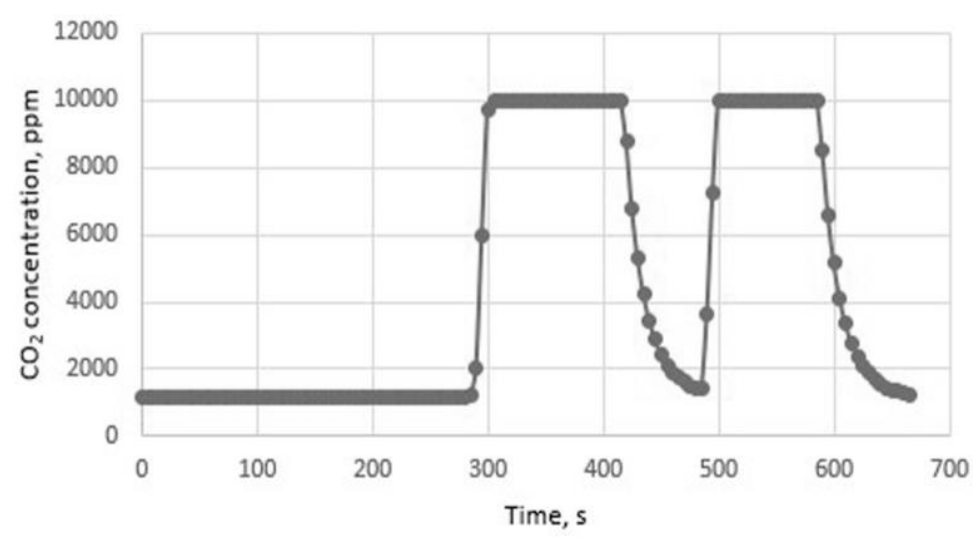

Figure 17. $\mathrm{CO}_{2}$ concentration in the stagnation zone under the mask

The study showed a difference in the measurement of $\mathrm{CO}_{2}$ concentration from the sensor in the front and back zone of the classroom. The reason is the configuration of the workplaces in the room: there were more occupants in the back zone. Of course, the effect of the ventilation system should be considered as well: it can provide a different mixing effect in the distinct areas of the classroom. The essential result is that both sensors registered a lower $\mathrm{CO}_{2}$ concentration in the air when participants were with masks.

The oxygen concentration also changed: the $\mathrm{O}_{2}$ in the air was depleted faster when participants wore masks. It may be related to the rapid breathing observed when wearing a mask (Roberge et al., 2012). Inhalations are also deeper, which is associated with both the high $\mathrm{CO}_{2}$ concentration of air from the microzone under the mask and the greater effort required to inhale through the pores of the mask. Fluctuations in the $\mathrm{O}_{2}$ concentration when breathing without a mask and the absence of such when participants are wearing masks also showed an altered breathing pattern.

The air temperature and relative humidity in the classroom at Sate 1 and Stage 2 also differ. However, it is difficult to determine that the presence of masks affected the temperature. The reason is that the radiant heat through the windows changed (increased) with the rising of the sun and the progress of the day. The effect of occupancy should also not be overlooked: before Stage 1, the room was empty, while Stage 2 followed Stage 1, in which the HVAC system warmed the room.

Nevertheless, the effect of wearing masks on the humidity in the room needs comments. Humidity was higher in Stage 2 due to the missing mask and the free passage of water vapour through the exhaled air from the lungs to the environment. The study in (Mansour et al., 2020) has shown that the relative humidity of the exhaled air is between $41.9-91.0 \%$. In the presence of a mask, the passage of water vapour from the exhaled air to the room is retained by the mask. This is why the accumulation of moisture in the microzone under the mask was also a subject of complaints by the participants. How the retained moisture under the mask affects comfort and its quantity is a matter of future evaluation.

The thermal image analysis clearly shows the increase in the temperature of the face under the mask over time. The heat transfer between the face and the mask is evidence of an increase in the temperature of the skin under the mask. From the thermograms of the masked persons it is clear that there is a proven difference between the surface temperatures of the mask at the beginning and middle of the wearing period, but not 
between the middle and the end of Stage 1. It is logical to conclude that heat transfer is very more intense at the beginning of wearing the mask, then slows down and probably follows the slow rate of rise in facial skin temperature under the mask.

The rise in facial skin temperature under the mask is unquestionable. Facial thermograms immediately after removing the masks clearly show elevated temperature areas compared to the reference thermograms before Stage 1. These are the areas around the mouth and nose. Thirteen of the 14 participants had a skin surface temperature above $37{ }^{\circ} \mathrm{C}$. In 9 thermograms, there was a temperature rise above $36.7^{\circ} \mathrm{C}$ in the neck area. In 5 participants, an increase in temperature was found in the upper part of the forehead and scalp. These results for the skin temperature are higher than the reported in (Mansour et al., 2020).

The temperature of the inner canthus of the eye is considered to be a reliable source of information about the core body temperature (Childs et al., 2012), although in (Teunissen et al., 2011), it was found that it differs by $1.80 \pm 0.89{ }^{\circ} \mathrm{C}$ from the temperature of the oesophagus, considered the "gold standard" in terms of core body temperature. The increase of the inner cantus of the eye's temperature is a sign of the thermophysiological reactions that occur in the body due to wearing the mask. Similar was the conclusions in (Yip et al., 2005), where an increment of the intraoral temperature of persons wearing masks, with $37.5^{\circ} \mathrm{C}$ and more, was found.

The change in the temperature of the inner cantus of the eye indicates that the presence of a mask affects the local rise of the facial temperature and triggers the body's thermoregulation system. Probably these reactions are related to the participants' complaints of discomfort and deteriorating thermal comfort during Stage 1. Future research is required to determine this effect in prolonged continuous standing with a face mask.

\section{Conclusions}

Our study used a combination of indoor environmental measurements and thermal imaging testing to study the effect of wearing surgical face masks on the comfort of the wearers and the indoor environment parameters. It was found that:

- The continuous wear of a face mask for 40-45 min in the classroom forms a stagnation microzone between the face and the mask. The microzone changes the breathing pattern, and the restricted flow motion affects the $\mathrm{CO}_{2}$ and $\mathrm{O}_{2}$ concentration in the classroom and the air relative humidity. The parameters of the microzone need further investigation.

- The continuous wear of a face mask for 40-45 min leads to an increment of the facial skin temperature, which could reach more than $37^{\circ} \mathrm{C}$ under the mask. The increment of the temperature of the inner cantus of the eye confirms that the face mask triggers the body's thermoregulation, causing thermophysiological reactions. Future research is required to determine this effect in prolonged continuous standing with a face mask.

Our future research will be dedicated to the effect of wearing different types of masks indoors (textile, N95, FFP2), using the same protocol. Another field of research will be measuring the $\mathrm{CO}_{2}$ concentration in the air, detained under different types of face masks, using a sensor that can measure very high concentration (30000 ppm or 
higher). The effect of the prolonged wearing of face masks (over $60 \mathrm{~min}$ ) on the thermophysiological comfort of the person indoors would also be considered.

Acknowledgements. This research and publication were supported by the Bulgarian Science Fund of the Ministry of Education and Science, Project No. КП-06-H47/3.

\section{REFERENCES}

[1] Aydin, O., Emon, B., Cheng, S., Hong, L., Chamorro, L. P., Saif, M. T. A. (2020): Performance of fabrics for home-made masks against the spread of COVID-19 through droplets: a quantitative mechanistic study. - Extreme Mechanics Letters 40: 100924.

[2] Buregyeya, E., Mitchell, E. M., Rutebemberwa, E., Colebunders, R., Criel, B., Kiguli, J., Nuwaha, F. (2012): Acceptability of masking and patient separation to control nosocomial tuberculosis in Uganda: a qualitative study. - Journal of Public Health 20(6): 599-606.

[3] Childs, C., Zu, M. M., Wai, A. P., Tsai, Y. T., Wu, S., Li, W. (2012): Infra-red thermal imaging of the inner canthus: correlates with the temperature of the injured human brain. Rapid determination of sexually transmitted infections by real-time polymerase chain reaction using microchip analyzer. - Engineering 5: 53-6.

[4] Chughtai, A. A., Seale, H., MacIntyre, C. R. (2013): Use of cloth masks in the practice of infection control-evidence and policy gaps. - Int J Infect Control 9(3): 1-12.

[5] Cowling, B. J., Ali, S. T., Ng, T. W., Tsang, T. K., Li, J. C., Fong, M. W., ... Leung, G. M. (2020): Impact assessment of non-pharmaceutical interventions against coronavirus disease 2019 and influenza in Hong Kong: an observational study. - The Lancet Public Health 5(5): e279-e288.

[6] Davies, A., Thompson, K. A., Giri, K., Kafatos, G., Walker, J., Bennett, A. (2013): Testing the efficacy of homemade masks: would they protect in an influenza pandemic? Disaster Medicine and Public Health Preparedness 7(4): 413-418.

[7] Desai, A. N., Aronoff, D. M. (2020): Masks and coronavirus disease 2019 (COVID-19). - JAMA 323(20): 2103-2103.

[8] EN 14683+AC (2019): Medical Face Masks - Requirements and Test Methods. European Committee for Standardization, Belgium.

[9] Feng, S., Shen, C., Xia, N., Song, W., Fan, M., Cowling, B. J. (2020): Rational use of face masks in the COVID-19 pandemic. - The Lancet Respiratory Medicine 8(5): 434436.

[10] Howard, J., Huang, A., Li, Z., Tufekci, Z., Zdimal, V., van der Westhuizen, H. M., ... \& Rimoin, A. W. (2021): An evidence review of face masks against COVID-19. Proceedings of the National Academy of Sciences 118(4).

[11] ISO 13485 (2016): Medical devices - Quality Management Systems-Requirements for Regulatory Purposes. - International Organization for Standardization, Switzerland.

[12] Konda, A., Prakash, A., Moss, G. A., Schmoldt, M., Grant, G. D., Guha, S. (2020): Aerosol filtration efficiency of common fabrics used in respiratory cloth masks. - ACS nano 14(5): 6339-6347.

[13] Kyung, S. Y., Kim, Y., Hwang, H., Park, J. W., Jeong, S. H. (2020): Risks of N95 face mask use in subjects with COPD. - Respiratory Care 65(5): 658-664.

[14] Lazzarino, A. I., Steptoe, A., Hamer, M., Michie, S. (2020): Covid-19: important potential side effects of wearing face masks that we should bear in mind. - The BMJ 369.

[15] Leung, G. M., Quah, S., Ho, L. M., Ho, S. Y., Hedley, A. J., Lee, H. P., Lam, T. H. (2004): A tale of two cities: community psychobehavioral surveillance and related impact on outbreak control in Hong Kong and Singapore during the severe acute respiratory syndrome epidemic. - Infection Control and Hospital Epidemiology 25(12): 1033-1041. 
[16] Liu, C., Diab, R., Naveed, H., Leung, V. (2020a): Universal public mask wear during COVID-19 pandemic: rationale, design and acceptability. - Respirology (Carlton, Vic.): 25(8): 895.

[17] Liu, C., Li, G., He, Y., Zhang, Z., Ding, Y. (2020b): Effects of wearing masks on human health and comfort during the COVID-19 pandemic. - IOP Conference Series: Earth and Environmental Science 531(1): 012034).

[18] Mansour, E., Vishinkin, R., Rihet, S., Saliba, W., Fish, F., Sarfati, P., Haick, H. (2020): Measurement of temperature and relative humidity in exhaled breath. - Sensors and Actuators B: Chemical 304: 127371.

[19] Rengasamy, S., Eimer, B., Shaffer, R. E. (2010): Simple respiratory protectionevaluation of the filtration performance of cloth masks and common fabric materials against 20-1000 nm size particles. - Annals of Occupational Hygiene 54(7): 789-798.

[20] Rieger, M. O. (2020): To wear or not to wear? Factors influencing wearing face masks in Germany during the COVID-19 pandemic. - Social Health and Behavior 3(2): 50.

[21] Roberge, R. J., Kim, J. H., Benson, S. M. (2012): Absence of consequential changes in physiological, thermal and subjective responses from wearing a surgical mask. Respiratory Physiology \& Neurobiology 181(1): 29-35.

[22] Scarano, A., Inchingolo, F., Lorusso, F. (2020): Facial skin temperature and discomfort when wearing protective face masks: thermal infrared imaging evaluation and hands moving the mask. - International Journal of Environmental Research and Public Health 17(13): 4624.

[23] Shakya, K. M., Noyes, A., Kallin, R., Peltier, R. E. (2017): Evaluating the efficacy of cloth facemasks in reducing particulate matter exposure. - Journal of Exposure Science \& Environmental Epidemiology 27(3): 352-357.

[24] Smith, P. B., Agostini, G., Mitchell, J. C. (2020): A scoping review of surgical masks and N95 filtering facepiece respirators: learning from the past to guide the future of dentistry. - Safety Science 131: 104920.

[25] Sofronova, D., Sofronov, Y., Angelova, R. A. (2021): Design of a Device for Measuring the Parameters of the Microenvironment under Protective Face Masks. - 2021 6th International Symposium on Environment-Friendly Energies and Applications (EFEA), Technical University of Sofia, Bulgaria, 24-26 March 2021, pp. 1-4.

[26] Teunissen, L. P. J., Daanen, H. A. M. (2011): Infrared thermal imaging of the inner canthus of the eye as an estimator of body core temperature. - Journal of Medical Engineering \& Technology 35(3-4): 134-138.

[27] Van der Sande, M., Teunis, P., Sabel, R. (2008): Professional and home-made face masks reduce exposure to respiratory infections among the general population. - PloS One 3(7): e2618.

[28] Wang, M. W., Cheng, Y. R., Ye, L., Zhou, M. Y., Chen, J., Feng, Z. H. (2020): The COVID-19 outbreak: the issue of face masks. - Infection Control \& Hospital Epidemiology 41(8): 974-975.

[29] World Health Organization (2020): Advice on the use of masks in the community, during home care and in healthcare settings in the context of the novel coronavirus ( 2019$\mathrm{nCoV}$ ) outbreak: interim guidance, 29 January 2020 (No. WHO/nCov/IPC_Masks/2020.1). - WHO, Geneva.

[30] Yip, W. L., Leung, L. P., Lau, P. F., Tong, H. K. (2005): The effect of wearing a face mask on body temperature. - Hong Kong Journal of Emergency Medicine 12(1): 23-27. 